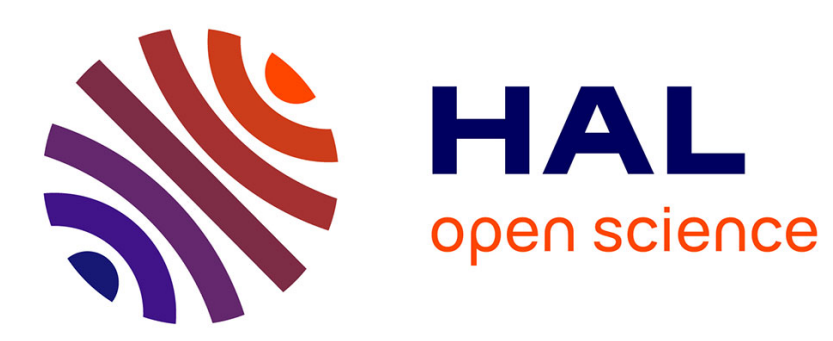

\title{
Mapping of an ophiolite complex 40 by high-resolution visible-infrared spectrometry
}

Combe J.P., P. Launeau, P. Pinet, D. Despan, E. Harris, G. Ceuleneer, C. Sotin

\section{To cite this version:}

Combe J.P., P. Launeau, P. Pinet, D. Despan, E. Harris, et al.. Mapping of an ophiolite complex 40 by high-resolution visible-infrared spectrometry. Geochemistry, Geophysics, Geosystems, 2006, 7, pp.11. 10.1029/2005GC001214 . hal-00112144

\section{HAL Id: hal-00112144 \\ https://hal.science/hal-00112144}

Submitted on 20 Dec 2021

HAL is a multi-disciplinary open access archive for the deposit and dissemination of scientific research documents, whether they are published or not. The documents may come from teaching and research institutions in France or abroad, or from public or private research centers.
L'archive ouverte pluridisciplinaire $\mathbf{H A L}$, est destinée au dépôt et à la diffusion de documents scientifiques de niveau recherche, publiés ou non, émanant des établissements d'enseignement et de recherche français ou étrangers, des laboratoires publics ou privés.

$$
\text { Copyright }
$$




\section{Mapping of an ophiolite complex by high-resolution visible- infrared spectrometry}

\section{Jean-Philippe Combe}

Laboratoire de Planétologie et Géodynamique, UMR-CNRS 6112, 2 chemin de la Houssiniere, BP 92208, F-44322 Nantes, France

Now at the Space Science Institute, Northwest Office, 22 Fiddler's Road, P. O. Box 667, Winthrop, Washington 98862, USA. (jean-philippe.combe@univ-nantes.fr)

\section{Patrick Launeau}

Laboratoire de Planétologie et Géodynamique, UMR-CNRS 6112, 2 chemin de la Houssiniere, BP 92208, F-44322 Nantes, France

\section{Patrick Pinet}

Laboratoire Dynamique Terrestre et Planétaire, 14 avenue Edouard-Belin, F-31400 Toulouse, France

\section{Daniela Despan}

Laboratoire de Planétologie et Géodynamique, UMR-CNRS 6112, 2 chemin de la Houssiniere, BP 92208, F-44322 Nantes, France

Now at the Laboratoire d'Etudes Spatiales et d'Instrumentation en Astrophysique, 5, place Jules Janssen, F-92195 Meudon, France

\section{Esther Harris and Georges Ceuleneer}

Laboratoire Dynamique Terrestre et Planétaire, 14 avenue Edouard-Belin, F-31400 Toulouse, France

\section{Christophe Sotin}

Laboratoire de Planétologie et Géodynamique, UMR-CNRS 6112, 2 chemin de la Houssiniere, BP 92208,

F-44322 Nantes, France

[1] The Sumail massif of the Oman peridotite has been surveyed by the high spectral resolution imager HyMap. The field measurements have been taken simultaneously to the HyMap campaign with a GER 3700 spectrometer. To compare the two data sets, further calibration and atmospheric correction are made through empirical line corrections. A continuum removal by a modified Gaussian model on reflectance is then performed for each pixel to minimize atmospheric scattering and shadowing effects. Classification from spectral distance is established using field observations and comparisons at full spectral resolution to identify peridotite subunits (harzburgites and dunites) and to distinguish plagioclase-wehrlites from gabbros. Detections of hydrothermal transformations of olivine in serpentines and their alteration in carbonates along fracture networks, characterized by narrow spectral signatures, validate the classification. This demonstrates the utility of the high spectral resolution and the development of appropriate processing methods for geological identifications.

Components: 4219 words, 8 figures, 1 table.

Keywords: hyperspectral; ophiolite; remote sensing; peridotite; alteration; mineralogy. 
Index Terms: 3042 Marine Geology and Geophysics: Ophiolites (8140); 3255 Mathematical Geophysics: Spectral analysis $(3205,3280)$.

Received 8 December 2005; Revised 8 April 2006; Accepted 20 April 2006; Published 1 August 2006.

Combe, J.-P., P. Launeau, P. Pinet, D. Despan, E. Harris, G. Ceuleneer, and C. Sotin (2006), Mapping of an ophiolite complex by high-resolution visible-infrared spectrometry, Geochem. Geophys. Geosyst., 7, Q08001, doi:10.1029/2005GC001214.

\section{Introduction}

[2] The Oman ophiolite is a fragment of oceanic lithosphere which was obducted onto the Arabian continental margin during late cretaceous times (Maestrichtian, i.e., about $70 \mathrm{Ma}$ ) [e.g., Coleman and Hopson, 1981]. The two main lithological units are partially serpentinized mantle peridotites and gabbroic-basaltic rocks from the overlying crustal section.

[3] Because of the extent of the area $\left(30,000 \mathrm{~km}^{2}\right)$ and to the extremely rugged topography, with elevations between 0 and $2500 \mathrm{~m}$, exhaustive sampling impossible. Remote sensing is able to provide more continuous lithological mapping and it is facilitated by the almost perfect rock exposure due to arid climate [Pontual, 1990].

[4] In addition, at smaller spatial scales, spectrometry can distinguish more subtle lithology variations [Hunt, 1977], essentially by absorption bands between 2100 and $2500 \mathrm{~nm}$. Interpretations have been already possible using multispectral (less than 10 channels) satellite imagery. Landsat Thematic Mapper (TM) which has 1 channel covering the 2090-2350 nm range was first used by Abrams et al. [1988]. With the JERS-1 OPS instrument, which has 3 channels in the $2100-2500 \mathrm{~nm}$ range (130 nm resolution), Denniss et al. [1994] and Pinet [1999] describe a larger number of lithologies: harzburgite and dunite forming the mantle and various gabbros intruded by wehrlite in the crustal section.

[5] In imaging spectroscopy, high spectral resolution is the key toward advanced lithology discrimination based on mineral identifications including all transformations from the fresh rock to its weathered skin. This is expected with hyperspectral (hundreds of channels) airborne instruments like HyMap (16 $\mathrm{nm}$ resolution in the 2100-2500 nm domain) and AVIRIS (10 nm resolution) [e.g., Cocks et al., 1998; Bodechtel, 2001; Swayze et al., 2003; Clark et al., 2003]. For peridotite fields, earlier hyperspectral investiga- tions have been made with AVIRIS data [e.g., Mustard, 1993; Chabrillat et al., 2000; Launeau et al., 2002, 2004]. This work will focus on the interest of the Modified Gaussian Model (MGM) [Sunshine et al., 1990] for an improved continuum removal [Combe et al., 2005; Pinet et al., 2006] to identify and map mineralogical zoning which could not be explained with classical remote sensing techniques.

\section{Data: HyMap Hyperspectral Images and GER 3700 Field Spectra}

[6] The Sumail massif of the Oman Ophiolite (Figures $1 \mathrm{a}$ and $1 \mathrm{~b}$ ) was surveyed with the imaging spectrometer HyMap on 4 and 6 December 2002 [Pinet et al., 2003, 2006], covering approximately a $10 \times 50 \mathrm{~km}$ area with a spatial resolution about $6 \mathrm{~m}$. The total data set is mainly composed of strips oriented NE-SW. Six were acquired the first day and eight the second day. This work is a preliminary study of the Maqsad area, undertaken on a small subarea of the survey, using part of two HyMap NE-SW strips (Figure 1c) acquired the first day.

[7] HyMap has 126 discrete channels between 448 and $2478 \mathrm{~nm}$ regularly distributed among three grating devices avoiding most of the water vapor absorptions at 1400 and $1900 \mathrm{~nm}$. Reflectance images and atmospheric correction with the atmosphere removal radiative transfer model (ATREM) [Gao et al., 1993; Cooperative Institute for Research in Environmental Sciences, 1999] and the Empirical Flat Field Optimal Reflectance Transformation (EFFORT) [Boardman, 1998] were provided by the HyVista team.

[8] In situ measurements have been taken with a GER 3700 spectrometer between 3 and 7 December 2002 at various locations in order to spectrally document identified lithologies of interest and surface properties The instrument has 640 channels between 315 and $2519 \mathrm{~nm}$ with a spectral sampling 


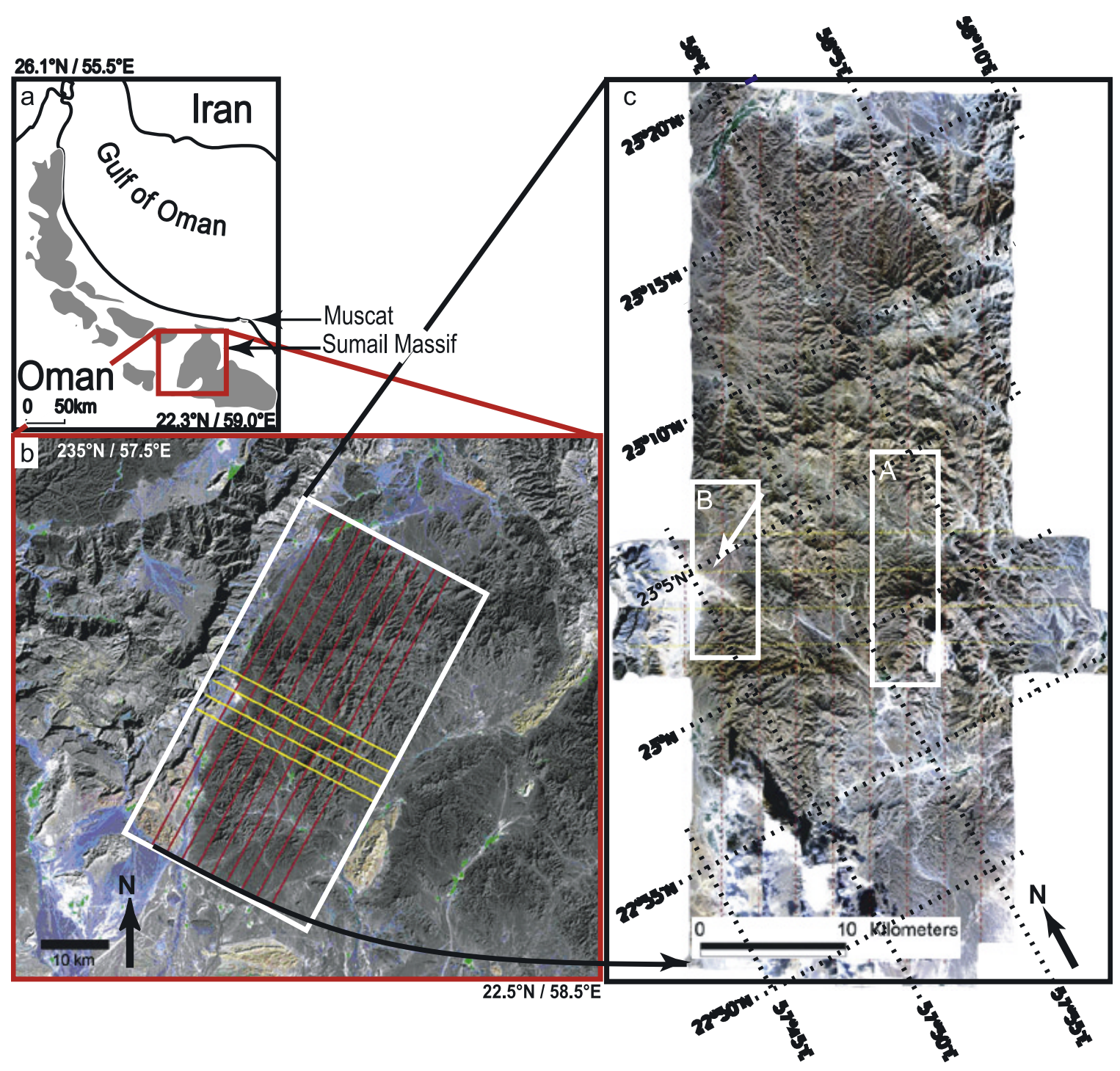

Figure 1. (a) Location of the Oman ophiolite and (b) the survey area of the Sumail massif by HyMap. (c) Two portions of the total data set that are presented in this study: Mantle peridotites and gabbroic-basaltic crustal rocks are investigated in A, and recent alteration is investigated in B. The reference site of bright and dark surfaces chosen for calibration is located by the white arrow.

comprised between 1.5 and $12 \mathrm{~nm}$. The ground field of view is about $100 \mathrm{~cm}^{2}$.

\section{Methods}

\subsection{Calibration to Ground Reflectance}

[9] In order to check the consistency of the calibration of the airborne data, field spectra have been acquired on the day and time of HyMap acquisition one bright and one dark spectrally homogeneous surfaces (arrow in Figure 1c). The bright one is a sebkha made of fine dust of peridotite while the dark one is a reg made of dark pebbles of peridotite covered by a thick crust of black desert varnish.
Both are easily located on the images. Despite the atmospheric correction provided by HyVista, airborne and field spectra (Figure 2) reveals that the bright surface levels are higher on HyMap spectra than on GER 3700 spectra (respectively 51 and $41 \%$ reflectance at maximum). In Figure 2 a local overestimate (atmospheric residue, a), a drop between 1700 and $1800 \mathrm{~nm}$ (b), an unexpected peak at the place of the $\mathrm{MgOH}$ absorption feature of serpentine (c), and a drop beyond $2400 \mathrm{~nm}$ (d) are clearly identified as artifacts on HyMap spectra. These lead us to apply additional empirical line corrections [e.g., Secker et al., 2001; Clark et al., 2002]. 


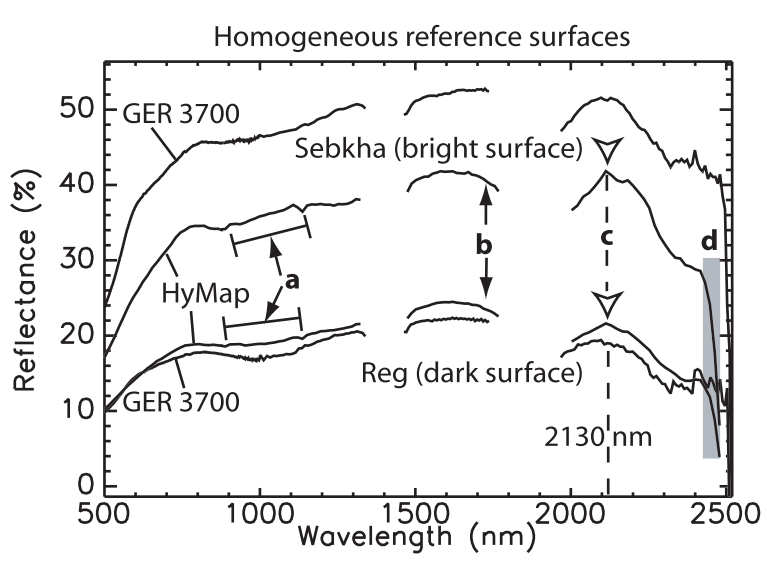

Figure 2. Reflectance of homogeneous surfaces of sebkha (bright) and reg (dark). Atmospheric absorption at 1400 and $1800 \mathrm{~nm}$ have been masked. An empirical correction is applied to remove the artifacts (localized by the letters and noted in the text) observed in HyMap reflectances.

\subsection{Continuum Removal Procedure}

[10] Topography contributes significantly to the photometric variations controlling the continuum. Without a high spatial resolution digital elevation model, an absolute correction using radiative transfer equations cannot be performed. Moreover, strong deviations are also induced by the different spatial resolutions and the distances to the target between field measurements and remote acquisitions [Friedl et al., 1995; Chen, 1999].

[11] For multiple data comparison and spectral analysis, continuum removal procedures are intensively used [Clark and Roush, 1984]. An improved method by way of the MGM was used successfully by Combe et al. [2005] to calculate a continuum insensitive to detector boundary's cut at both ends. The MGM fits the entire spectrum (reflectance $R_{\mathrm{k}}$ at channel number $k$ ) of an image by a set of $n$ Gaussian curves defined by their position $(\operatorname{center} \mu)$,

Table 1. Initial Set of User-Defined Parameters for Eight Gaussian Absorption Bands

\begin{tabular}{cc}
\hline Center Position, nm & Width, nm \\
\hline 490 & 200 \\
650 & 200 \\
1000 & 150 \\
1150 & 150 \\
1500 & 120 \\
1900 & 170 \\
2100 & 40 \\
2300 & 150 \\
\hline
\end{tabular}

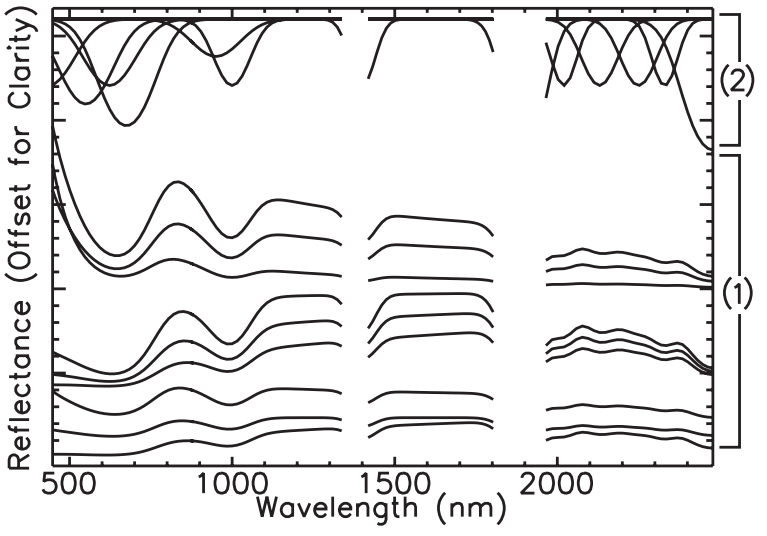

Figure 3. Importance of continuum removal. These synthetic spectra have different continuum shapes (1) despite having exactly the same absorption bands (2).

width $(\sigma)$ and amplitude (strength $s$ ) and, according to Sunshine et al. [1990], the best continuum is assumed to be linear in wavelength $\lambda$ ( $a$ and $b$ are the slope and the intercept respectively). As a result, the continuum retrieved by MGM becomes independent from the absorptions [Sunshine and Pieters, 1993].

$$
\ln \left(\mathrm{R}_{\mathrm{k}}\right)=\left(\mathrm{a} \lambda_{\mathrm{k}}^{-1}+\mathrm{b}\right)+\sum_{\mathrm{i}=1}^{\mathrm{n}} \mathrm{s}_{\mathrm{i}} \cdot \exp \left[-\frac{\left(\lambda_{\mathrm{k}}-\mu_{\mathrm{i}}\right)^{2}}{2 \sigma_{\mathrm{i}}^{2}}\right]
$$

[12] The algorithm starts with an initial solution allowing the best fit for the maximum number of pixels. The eight Gaussian curves (Table 1) have been chosen to provide an acceptable fit on the larger number of spectra with a minimum of absorption bands. Modifying these parameters may cause iterations to often stop prematurely, leading to a resulting continuum function not well constrained.

[13] Figure 3 demonstrates the importance of the continuum removal. This permits direct comparisons of spectra from various images [Combe et al., 2005]. It consists of subtracting the continuum function $a \lambda_{\mathrm{k}}^{-1}+b$ of equation (1) to spectra in logarithm reflectance space.

\subsection{Geological Mapping}

\subsubsection{Classification by Spectral Distance}

[14] A classification is performed with reference spectra chosen among the hyperspectral images. For each rock of interest, an average spectrum is calculated from several image pixels (Figure 4) at the location given by the geological map by Amri 


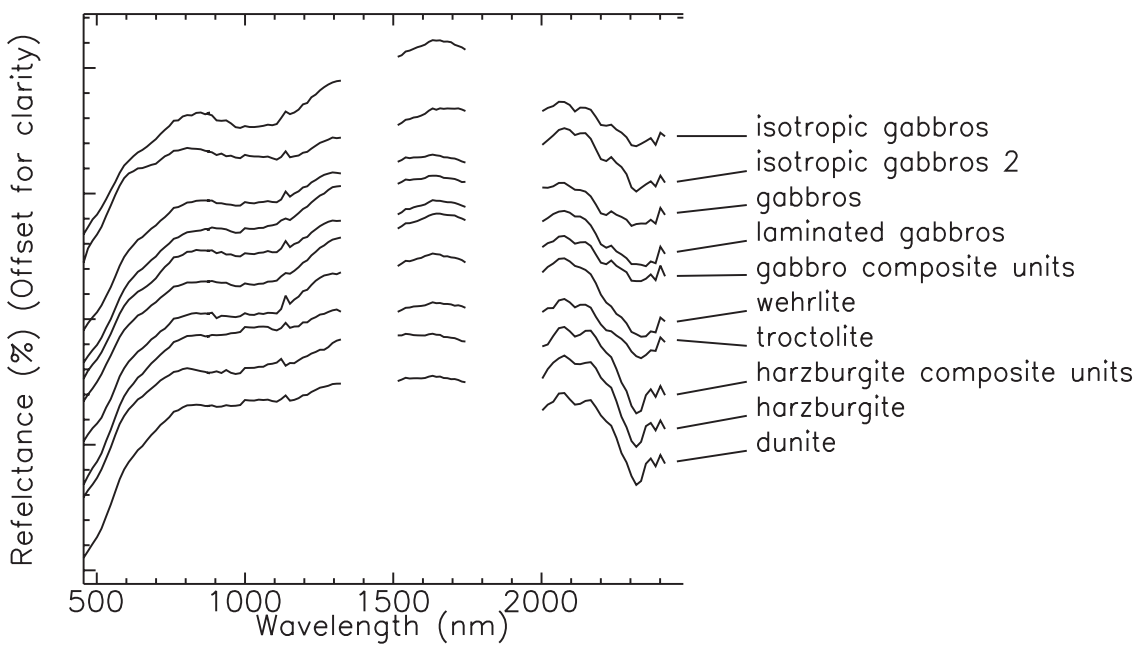

Figure 4. Spectra of the main lithologies measured by HyMap after continuum removal by MGM. Gabbros are the first five, and peridotites are the last five.

et al. [1994]. These pixels were chosen close to sampling locations to avoid large interpolations. Comparison uses a normalized spectral distance $I D$ [Launeau et al., 2002] by considering spectra as vectors $\boldsymbol{v}$ (image reference spectra) and $\boldsymbol{w}$ (image tested spectra):

$$
I D(\vec{v}, \vec{w})=\sqrt{\frac{1}{N} \sum_{\lambda}\left[\frac{R_{v}(\lambda)-R_{w}(\lambda)}{R_{w}(\lambda)}\right]^{2}}=\frac{\|\vec{v}-\vec{w}\|}{\|\vec{w}\|},
$$

where $R$ is the reflectance, $N$ the number of channels and $\lambda$ the wavelengths. Spectral distance between each spectrum of the image and the reference spectra provide a relative quantification. Unlike the spectral angle mapping, this distance allows us to distinguish albedo variations as discussed by Combe et al. [2005].

\subsubsection{Serpentine Index}

[15] Because of common hydration of their primary minerals, peridotites show spectral features of the hydroxyl group (OH) in the range 2200-2400 nm [King and Clark, 1989; Swayze, 2004]. On the other hand, serpentine does not preserve the main absorption bands of the minerals from which it has been formed (Figure 4), thus the occurrence of serpentine might hamper the detection of the absorption bands of olivine and pyroxenes around $1000 \mathrm{~nm}$.

[16] Serpentinized minerals have several absorption bands in spectra between 2100 and $2500 \mathrm{~nm}$. The strongest absorptions are around $2300 \mathrm{~nm}$ as can be seen in Figure 5a, but they are not a diagnostic of serpentinized minerals because other absorption processes occur at these wavelengths (e.g., Figure 5b). The small absorption isolated near $2130 \mathrm{~nm}$ due to $\mathrm{Mg}-\mathrm{OH}$ and giving a $\mathrm{M}$ shape to spectra is more reliable to presence of serpentine. When narrow absorptions features like these are available, the absorption band depth can be calculated using the ratio between the average reflectance of the shoulders at 2077 and $2166 \mathrm{~nm}$ and the reflectance of the minimum at $2130 \mathrm{~nm}$. To have zero values when serpentinization is low, we have defined the following index:

$$
\frac{R_{2077}+R_{2166}}{2 \times R_{2131}}-1 \text {. }
$$

\subsubsection{Mapping Alteration and Magnesite}

[17] The weathering is commonly seen as a complication of the lithology discrimination by remote sensing. However, it may also map the extension of some processes of low-grade metamorphism which would have been missed without such high spectral resolution images. For example the magnesite is locally an abundant alteration product of serpentine related to low-grade metamorphism and recent water circulations that have concentrated it along faults. Like other carbonates, it shows useful narrow absorptions features due to $\mathrm{C}-\mathrm{O}$ bonds [Hunt, 1977]. Two of them vary from $2305 \mathrm{~nm}$ to $2335 \mathrm{~nm}$ and from $2449 \mathrm{~nm}$ to $2453 \mathrm{~nm}$, from $\mathrm{MgCO}_{3}$ (magnesite) and $\mathrm{MgCa}\left(\mathrm{CO}_{3}\right)_{2}$ (dolomite) to $\mathrm{CaCO}_{3}$ (calcite) end-members. Dolomites most enriched in $\mathrm{Mg}$ are in effect not distinguishable from magnesite on Hymap data. However, like for calcite and dolomite [Launeau et al., 2004], low concentrations 

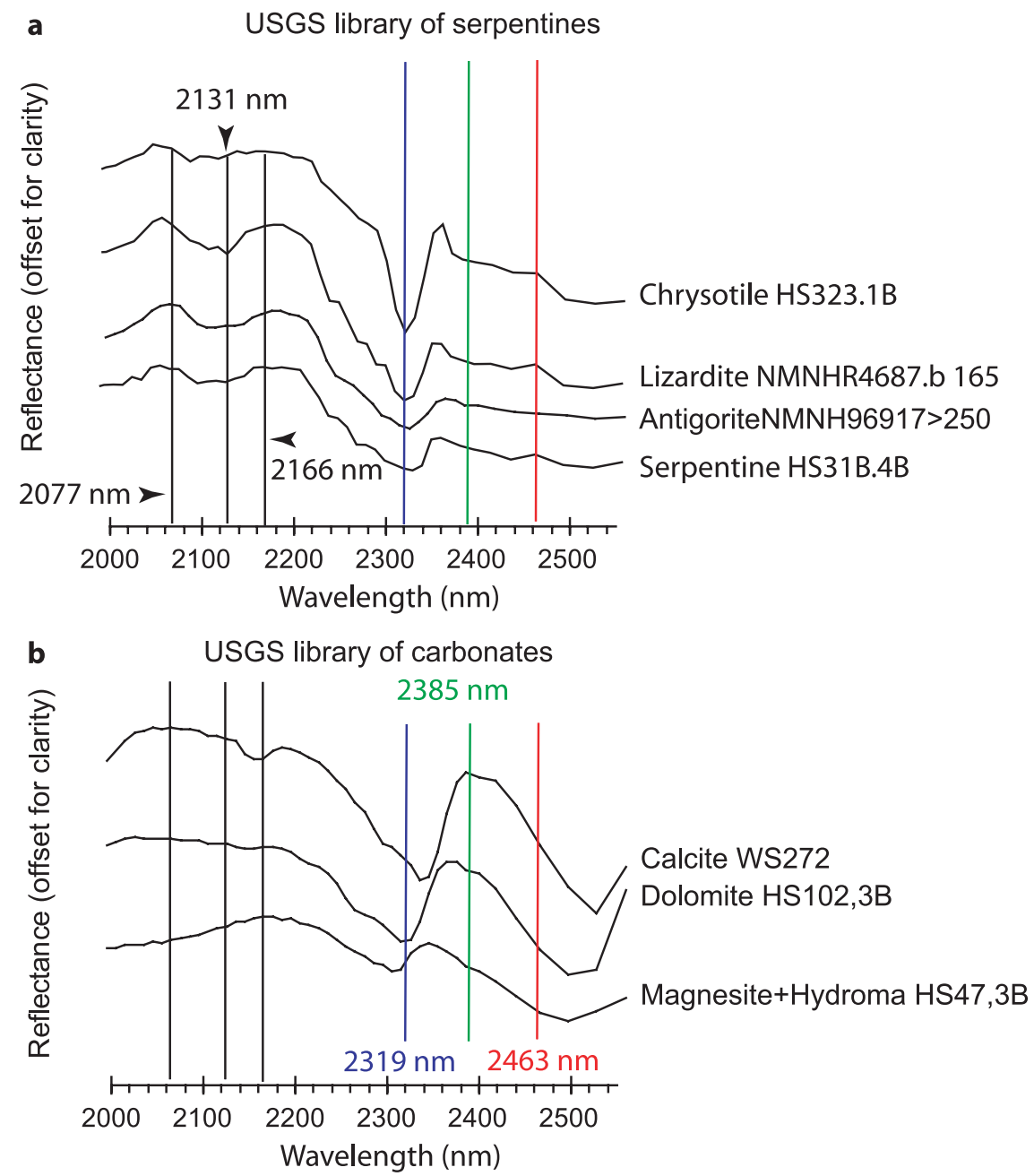

Figure 5. USGS spectra of (a) serpentines and (b) carbonates used to build appropriate index and color composite for mapping.

of magnesite can be deduced from an appropriate color composition centered on the narrow peak of reflectance at $2384 \mathrm{~nm}$ constrained between the two absorptions bands of the magnesite (or dolomite) at $2305 \mathrm{~nm}$ and $2447 \mathrm{~nm}$ (Figure 5b).

\section{Results}

\subsection{Lithological Mapping}

[18] Reflectance images in Figure 6a are dominated by topographic effects. Moreover, diversity of the surface composition is not sufficient to provide a good contrast because all petrologic units present similar spectra with absorption bands mainly due to $\mathrm{Fe}^{2+}$ electronic processes in the range 700$1300 \mathrm{~nm}$ (Figure 4).

[19] Removing a continuum by MGM (Figure 6b) minimizes spatial variations of apparent reflectance due to differences of illumination conditions when strong effects of rough topography occur (Figure 6a). Main lithological identifications (gabbros, harzburgite, dunite) are then obtained by a simple color composition at $789 \mathrm{~nm}$ (green), $983 \mathrm{~nm}$ (red) and $2304 \mathrm{~nm}$ (blue), chosen along weak variations around the $1000 \mathrm{~nm}$ absorption feature (Figure 6b). They are deduced from direct ground observations and from control point on the geological map of Amri et al. [1994]. It reveals harzburgite in green and dunite in yellow. Since gabbros and the plagioclasewehrlite do not have deep narrow absorption feature at $2304 \mathrm{~nm}$ they appear blue (Figure 6b).

[20] The boundary between peridotites and crustal lithologies is very sharp and is always underlined by a dunitic horizon. These cartographic results agree with the conclusions drawn from the global mapping of the massif established by means of 

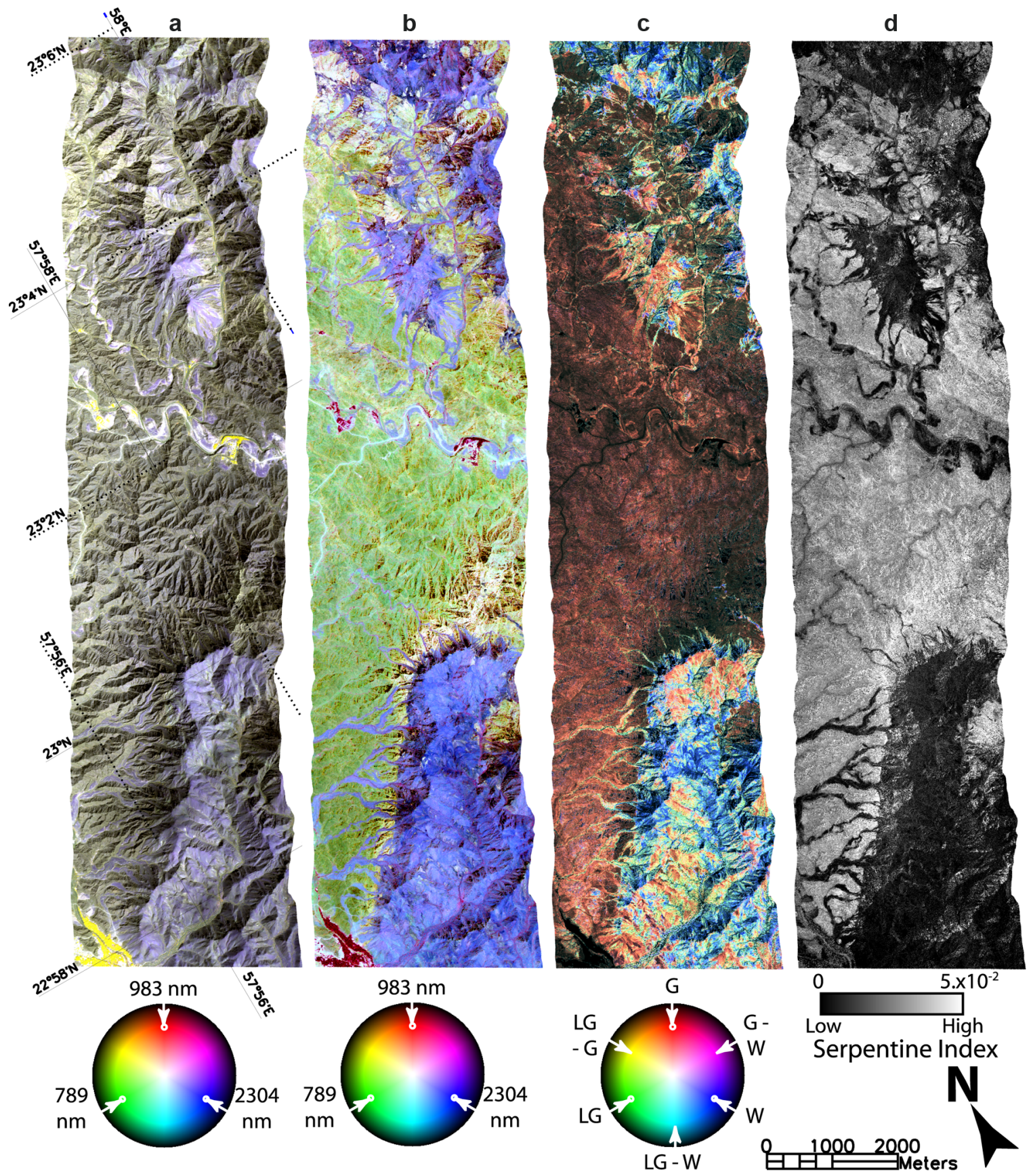

Figure 6. Lithological identifications: (a) Color composite of reflectances. Purple, gabbros; yellow, peridotites and vegetation; dark: shadow. (b) Color composite of reflectance after continuum removal by MGM. Yellow, dunites; green, harzburgite; blue, gabbros; red, vegetation. (c) Gabbroic rocks classification by spectral distance. G, layered gabbros; LG, laminated gabbros; W, wehrlite. (d) Serpentine. Bright corresponds to high serpentinization.

various color composites derived from scaled reflectance data [Pinet et al., 2003, 2005].

[21] Since we are looking at subtle differences between almost similar spectra, $I D$ tend to be zero and we rather display the inverse of $I D$ which increases strongly when spectra become closer. The spectral distance to three average spectra of identified units are presented in Figure 6c: they are laminated gabbros, layered gabbros and plagioclase-wehrlite. Layered gabbros (rocks formed in a magma chamber) form well-delimited units while a petrologic continuity is found between plagioclase-wehrlite and laminated gabbros (interpreted as intrusive rocks). This petrological continuity is 
a
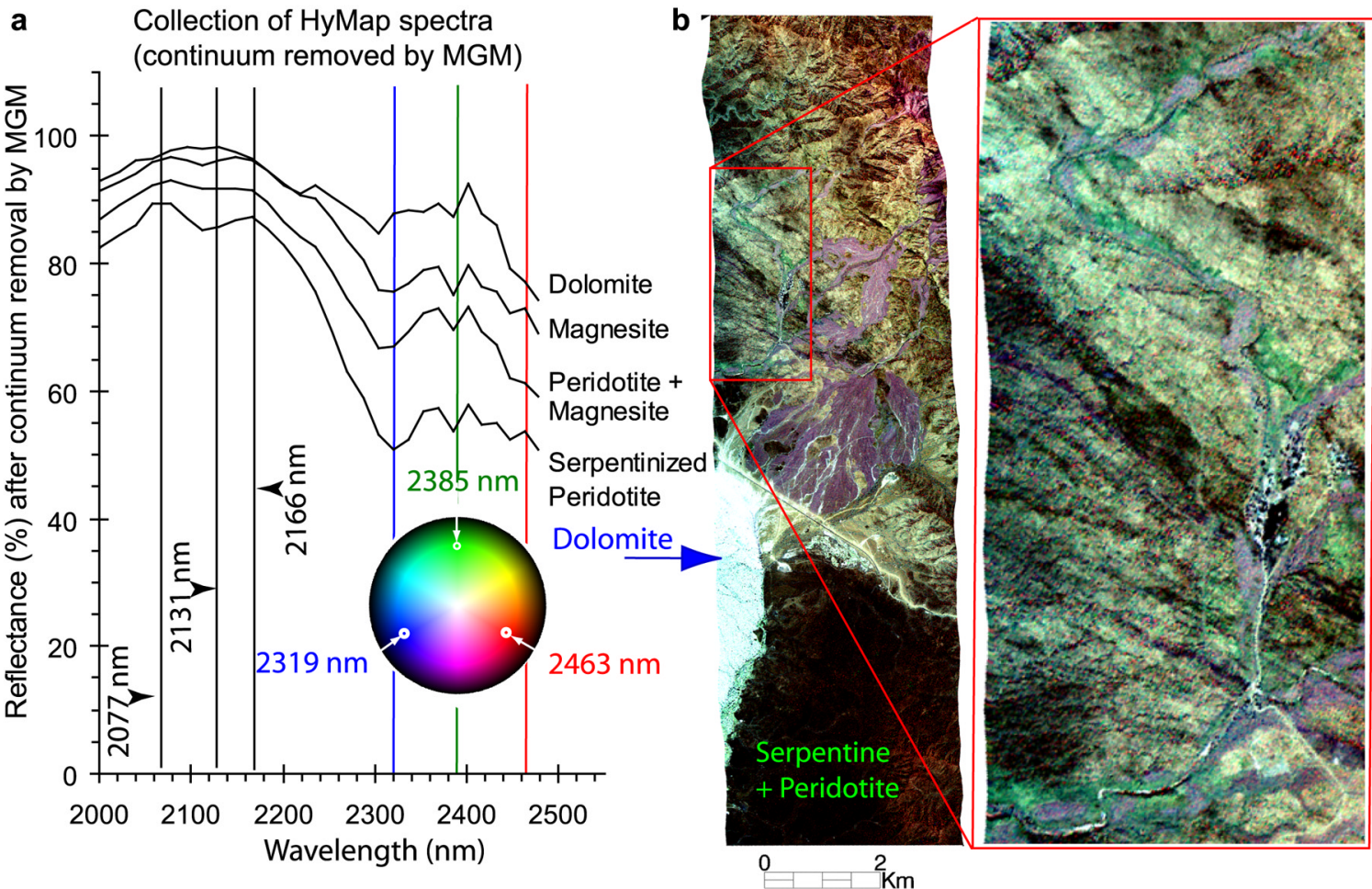

Figure 7. Spectra of carbonates and serpentinized minerals. (a) Collected from the Hymap image. (b) Alteration and magnesite mapping. Pure magnesite appears medium green along the wadi (bottom right). The dolomite (blue arrow) is carried from the Jabal al Akhdar massif on the northwest, invisible on the image.

in agreement with formation conditions characterized by a magmatic origin drastically contrasted with harzburgites and dunites which are residual peridotites [Girardeau and Francheteau, 1993]. In the western part of the image, all gabbroic rocks are present on steep slopes of mountains and found in quaternary deposits made of rubbles and gravels well contrasted with the surrounding peridotites.

\subsection{Serpentine Mapping}

[22] The serpentine index (Figure 6d) reveals higher amounts of serpentine in harzburgite and dunite areas. This might indicates that the main peridotites are deeply affected by hydrothermal processes and serpentine formations. Gabbro areas and more surprisingly late intrusive body of wehrlite are relatively poor in serpentine: they probably never get altered by such strong circulation of water which was not mapped before this work.

[23] The presence of olivine in dunite and harzburgite areas (Figure 6b) is confirmed by the detection of its common product of hydrothermal transformation: serpentine (narrow $\mathrm{Mg}-\mathrm{OH}$ absorption feature). Uncertain zonings of the NE [Denniss et $a l ., 1994]$ are now well identified and attributed to a late low-grade metamorphism detected by narrow (30 $\mathrm{nm}$ width) absorption features of magnesite, alteration product of serpentine. This kind of validation by the mineralogical transformation path is possible with HyMap because its spectral resolution of $16 \mathrm{~nm}$ is a fraction of the absorption bands of interest.

\subsection{Alteration Mapping}

[24] In Figure 7, some dolomite (white to pale green) appears in the valley on the western border of the peridotite as pebbles of sedimentary rocks coming from the Jabal al Akhdar massif. The magnesite can be fully identified in the harzburgite along wadis (medium green color) where it forms large concretions, probably where the water table is close to the surface. In the surrounding harzburgite, the spectral signature of magnesite is quite weak but highlights areas of low-grade metamorphism. By contrast, the southern harzburgite (Figure 7) are very dark, indicating that no such low-grade metamorphism was superimposed on the first serpentine transformation. The detection of that low content in magnesite is possible after continuum removal by MGM (Figure 8a) because the two absorption bands of carbonates near 2300 and $2500 \mathrm{~nm}$ are 
a

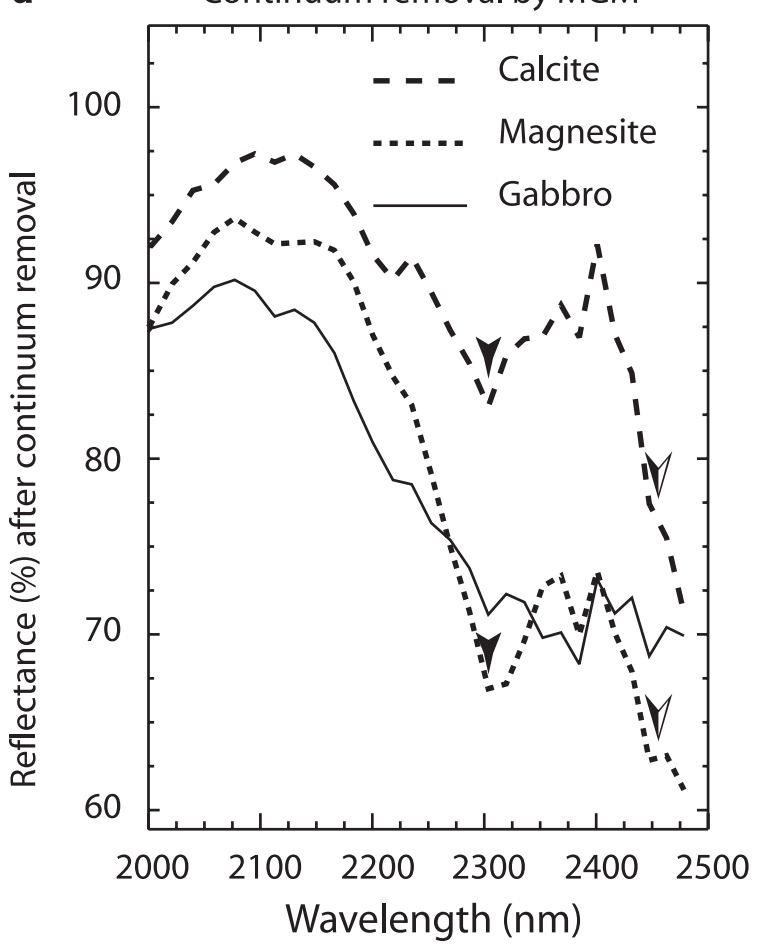

b Classical continuum removal by straigth lines

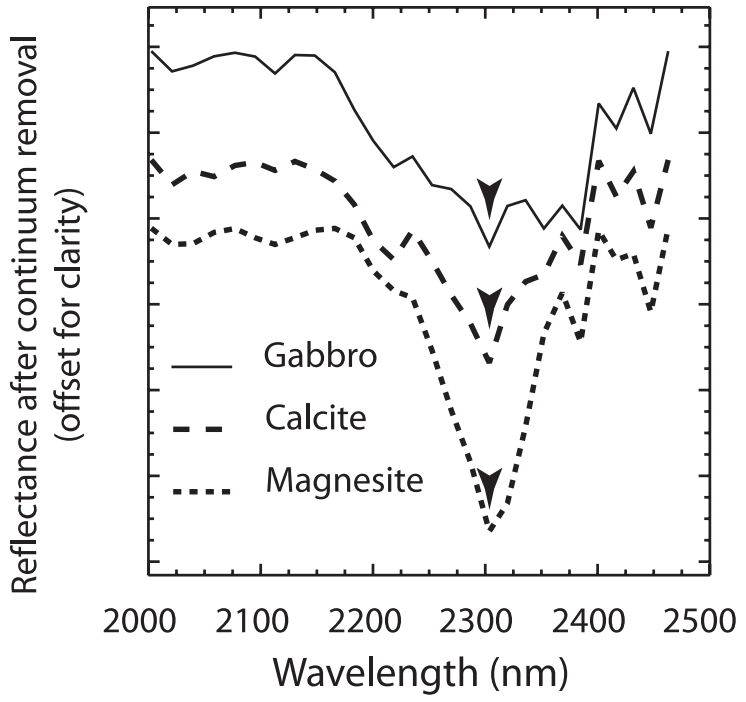

Figure 8. Spectral signatures of two carbonates (calcite and magnesite) and gabbros extracted from the HyMap data set. (a) After continuum removal by MGM, carbonates show two deep absorption bands near 2300 and 2450. (b) Classical continuum removal erases any absorption band near the limit of the spectra at $2470 \mathrm{~nm}$ and enhances the local minimum near $2300 \mathrm{~nm}$ for every spectra. well preserved and are different of gabbro spectra (negative slope toward longer wavelengths). This would not be possible with a classical continuum removal modeled by straight lines that are tangential to the spectra [e.g., Clark and Roush, 1984], like the one that is implemented in the ENVI software, because at the edge of the spectra, this continuum is sensitive to shape of the absorption bands. Indeed, in Figure 8b, both carbonate and gabbro spectra show a minimum near $2300 \mathrm{~nm}$ resulting in an ambiguity which prevents from the use of reference points for defining a classical continuum. The shape of spectra at $2385 \mathrm{~nm}$ indicates a systematic artifact, but its amplitude is about the same over the whole image. Thus it does not lead to an error on the magnesite index as it is only used to map relative variations.

\section{Conclusion}

[25] Mapping lithologies of the Oman ophiolite emphasizes that high spectral resolution images are well appropriate in geology and that the increase in information demands the implementation of new processing methods.

[26] Like previous works using multispectral data (JERS OPS by Denniss et al. [1994] and Landsat TM by Dromard [1999] and Pinet [1999]), the main lithological units (gabbros and peridotites) are mapped. However, unlike those works, direct identification of lithologies having narrow absorption bands is made possible from hyperspectral observation data. Moreover, that determination is enhanced by MGM continuum removal which minimizes illumination condition variations and facilitates the interpixel comparison by means of straight spectral distance measurements.

[27] From a geological viewpoint, the ability to map serpentines in great detail can improve the knowledge of earlier hydrothermalism while maps of ultimate product of alteration, like the magnesite in peridotite, can outline various rate of massif exhumation.

[28] This work also contributes to a better definition of spectral resolution requirements for geological applications. In this preliminary analysis of HyMap data acquired over the ophiolitic Sumail massif, geological classification by spectral distance is performed on the whole spectral domain while spectral analysis of secondary minerals is mainly focused on a restricted spectral range between 2000 and $2500 \mathrm{~nm}$. This demonstrates that the same hyperspectral image can be used for 
multiple objectives and analyzed through different approaches requiring high spectral resolution on the whole spectral domain.

\section{Acknowledgments}

[29] This work has been made possible thanks to the funding allocated by the French Ministry of Research to the Hypergemme project in the frame of the national program "ACI Observation de la Terre" 2001-2004. We also thank HyVista and Fugro companies for their efficiency during the airborne campaign in Oman, with a special mention for the pilots.

\section{References}

Abrams, M. J., D. A. Rothery, and A. Pontual (1988), Mapping in the Oman ophiolite using enhanced Landsat Thematic Mapper images, Tectonophysics, 151, 387-401.

Amri, I., G. Ceuleneer, and M. Monnereau (1994), Geological map of the crustal and mantle section of Sumail massif Oman ophiolite, Obs. Midi-Pyrénées, Cent. Natl. de la Rech. Sci., Toulouse, France.

Boardman, J. W. (1998), Post-ATREM polishing of AVIRIS apparent reflectance data using EFFORT: A lesson in accuracy versus precision, in Proceedings of the 8th JPL Airborne Earth Science Workshop, JPL Publ., 99, 53.

Bodechtel, J. (2001), Requirements on optical sensors for quantitative definition of surface parameters multispectralhyperspectral, Adv. Space Res., 28, 241-250.

Chabrillat, S., P. C. Pinet, G. Ceuleneer, P. E. Johnson, and J. F. Mustard (2000), Rondaperidotite massif: Methodology for its geological mapping and lithological discrimination from airborne hyperspectral data, Int. J. Remote Sens., 21(12), 2363-2388.

Chen, J. M. (1999), Spatial scaling of a remotely sensed surface parameter by contexture, Remote Sens. Environ., 69, 30-42.

Clark, R. N., and T. L. Roush (1984), Reflectance spectroscopy: Quantitative analysis techniques for remote sensing applications, J. Geophys. Res., 89, 6329-6340.

Clark, R. N., G. A. Swayze, K. E. Livo, R. F. Kokaly, T. V. V. King, J. B. Dalton, J. S. Vance, B. W. Rockwell, T. Hoefen, and R. R. McDougal (2002), Surface reflectance calibration of terrestrial imaging spectroscopy data: A tutorial using AVIRIS, in Proceedings of the 10th JPL Airborne Earth Science Workshop, JPL Publ., 02-1.

Clark, R. N., G. A. Swayze, K. E. Livo, R. F. Kokaly, S. J. Sutley, J. B. Dalton, R. R. McDougal, and C. A. Gent (2003), Imaging spectroscopy: Earth and planetary remote sensing with the USGS Tetracorder and expert systems, J. Geophys. Res., 108(E12), 5131, doi:10.1029/ 2002JE001847.

Cocks, T., R. Jenssen, A. Stewart, I. Wilson, and T. Shields (1998), The HyMap ${ }^{(i x}$ airborne hyperspectral sensor: The system, calibration and performance, paper presented at 1st EARSEL Workshop on Imaging Spectroscopy, Eur. Assoc. of Remote Sens. Lab., Zurich, Germany.

Coleman, R. G., and C. A. Hopson (1981), Introduction to the Oman ophiolite, J. Geophys. Res., 86, 2495-2496.

Combe, J.-P., P. Launeau, V. Carrère, D. Despan, V. Méléder, L. Barillé, and C. Sotin (2005), Mapping microphytobenthos biomass by non-linear inversion of visible-infrared hyperspectral images, Remote Sens. Environ., 98, 371-387.

Cooperative Institute for Research in Environmental Sciences (1999), CIRES Atmosphere Removal Program (ATREM), user's guide, version 3.1., Cent. for the Study from Space, Univ. of Colo., Boulder.

Denniss, A. M., D. A. Rothery, G. Ceuleneer, and I. Amri (1994), Lithological discrimination using Landsat and JERS-1 SWR data in the Oman ophiolite, paper presented at Tenth Thematic Conference on Geological Remote Sensing, Environ. Res. Inst. of Mich., San Antonio, Tex.

Dromard, S. (1999), Cartographie géologique par couplage des observations multispectrales satellitaires JERS-1 acquises sur l'Oman avec des données par spectrométrie de terrain, mémoire de DESS “Applications des technologies spatiales," report, 58 pp., Univ. Louis Pasteur, Strasbourg, France.

Friedl, M. A., F. W. Davis, and J. Michaelsen (1995), Scaling and uncertainty in the relationship between the NDVI and land surface biophysical variables: An analysis using a scene simulation model and data from FIFE, Remote Sens. Environ., 54, 233-246.

Gao, B.-C., K. B. Heidebrecht, and A. F. H. Goetz (1993), Derivation of scaled surface reflectances from AVIRIS data, Remote Sens. Environ., 44, 165-178.

Girardeau, J., and J. Francheteau (1993), Plagioclase-wehrlites and peridotites on the East Pacific Rise (Hess Deep) and the Mid-Atlantic Ridge (DSDP Site 334): Evidence for magma percolation in the oceanic upper mantle, Earth Planet. Sci. Lett., 115, 137-149.

Hunt, G. R. (1977), Spectral signatures of particulate minerals in the visible and near infrared, Geophysics, 42, 501-513.

King, T. V. V., and R. N. Clark (1989), Spectral characteristic of chlorites and $\mathrm{Mg}$-serpentines using high-resolution reflectance spectroscopy, J. Geophys. Res., 94, 13,99714,008 .

Launeau, P., J. Girardeau, and C. Sotin (2002), Cartography of the Ronda peridotite (Spain) by hyperspectral remote sensing, Bull. Soc. Geol. Fr., 173(6), 491-508.

Launeau, P., J. Girardeau, C. Sotin, and J. Tubia (2004), Comparison between field measurements and airborne visible and infrared mapping spectrometry (AVIRIS and HyMap) of the Ronda peridotite massif (south-west Spain), Int. J. Remote Sens., 25, 2773-2792.

Mustard, J. (1993), Relationships of soil, grass, and bedrock over the Kaweah serpentinite melange through spectral mixture analysis of AVIRIS data, Remote Sens. Environ., 44(23), 293-308.

Pinet, P. C. (1999), Hyperspectral methodologies applied to multi/superspectral data for rock surface mineralogy mapping, paper presented at the Workshop "Atelier Hyperspectral," Cent. Natl. d'Etudes Spatiales, Fourquevaux, France.

Pinet, P. C., et al. (2003), Hyperspectral remote sensing approach for rock surface mineralogy mapping in arid environment, paper presented at IUGG XXXIII General Assembly, Int. Union of Geod. and Geophys., Sapporo, Japan.

Pinet, P. C., et al. (2005), Hyperspectral survey for mantle rock surface mineralogy mapping in arid environment: The case of the Maqsad (Oman) peridotitic massif and implications for the mafic exposed units of Mars, paper presented at EGU General Assembly, Eur. Geosci. Union, Vienna.

Pinet, P. C., et al. (2006), Mantle rock surface mineralogy mapping in arid environment from imaging spectroscopy: The case of the Maqsad peridotitic massif in Oman and implications for the spectroscopic study of exposed mafic units of Mars, Proc. Lunar Planet. Sci. Conf., 37th, Abstract 1346.

Pontual, A. (1990), Lithological information in remotely sensed images and surface weathering in arid regions, Ph.D., Open Univ., Milton Keynes, U. K. 
Secker, J., K. Staenz, R. P. Gauthier, and P. Budkewitsch (2001), Vicarious calibration of airborne hyperspectral sensors in operational environments, Remote Sens. Environ., 76, $81-92$.

Sunshine, J., and C. M. Pieters (1993), Estimating modal abundances from spectra of natural and laboratory pyroxene mixtures using the modified Gaussian model, J. Geophys. Res., 98, 9075-9087.

Sunshine, J., C. M. Pieters, and S. F. Prat (1990), Deconvolution of mineral absorption bands: An improved approach, J. Geophys. Res., 93, 6955-6966.
Swayze, G. A. (2004), Using reflectance spectroscopy to evaluate minerals of environmental concern, in Infrared Spectroscopy in Exploration, Geochemistry and Remote Sensing, Short Course Ser, vol. 33, edited by P. L. King, M. S. Ramsey, and G. A. Swayze, pp. 181-196, Mineral. Assoc. of Can., Ottawa.

Swayze, G. A., R. N. Clark, A. F. H. Goetz, T. G. Chrien, and N. S. Gorelick (2003), Effects of spectrometer band pass, sampling and signal-to-noise ratio on spectral identification using the Tetracorder algorithm, J. Geophys. Res., 108(E9), 5105, doi:10.1029/2002JE001975. 